\title{
Narrative review of Ebstein's anomaly beyond childhood: Imaging, surgery, and future perspectives
}

\author{
Stephan Neumann ${ }^{1}$, André Rüffer ${ }^{2}$, Jörg Sachweh ${ }^{2}$, Daniel Biermann ${ }^{2}$, Jochen Herrmann ${ }^{3}$, \\ Michael Jerosch-Herold ${ }^{4}$, Mark Hazekamp ${ }^{5}$, Christoph Sinning ${ }^{6}$, Elvin Zengin ${ }^{6}$, Stefan Blankenberg $^{6}$, \\ Evaldas Girdauskas ${ }^{7}$, Hermann Reichenspurner ${ }^{7}$, Torben Kehl ${ }^{1}$, Götz Müller ${ }^{1}$, Rainer Kozlik-Feldmann ${ }^{1}$, \\ Carsten Rickers ${ }^{8}$
}

${ }^{1}$ Department of Pediatric Cardiology, University Heart \& Vascular Center Hamburg, Hamburg, Germany; ${ }^{2}$ Surgery for Congenital Heart Disease, University Heart \& Vascular Center Hamburg, Hamburg, Germany; ${ }^{3}$ Department of Pediatric Radiology, University Medical Center HamburgEppendorf, Hamburg, Germany; ${ }^{4}$ Brigham and Women's Hospital, Harvard Medical School, Boston, USA; ${ }^{5}$ Department of Cardiothoracic Surgery, Leiden University Medical Center, Leiden, The Netherlands; ${ }^{6}$ Department of Cardiology, University Heart \& Vascular Center Hamburg, Hamburg, Germany; ${ }^{7}$ Department of Cardiovascular Surgery, University Heart \& Vascular Center Hamburg, Hamburg, Germany; ${ }^{8}$ Adult Congenital Heart Disease Section, University Heart \& Vascular Center Hamburg, Hamburg, Germany

Contributions: (I) Conception and design: S Neumann, C Rickers; (II) Administrative support: None; (III) Provision of study materials or patients: None; (IV) Collection and assembly of data: None; (V) Data analysis and interpretation: None; (VI) Manuscript writing: All authors; (VII) Final approval of manuscript: All authors.

Correspondence to: Carsten Rickers, MD. University Heart \& Vascular Center Hamburg, Adult Congenital Heart Disease Section, Martinistr. 52, 20246 Hamburg, Germany. Email: c.rickers@uke.de.

\begin{abstract}
Ebstein's anomaly is a rare congenital heart disease with malformation of the tricuspid valve and myopathy of the right ventricle. The septal and inferior leaflets adhere to the endocardium due to failure of delamination. This leads to apical displacement of their hinge points with a shift of the functional tricuspid valve annulus towards the right ventricular outflow tract with a possibly restrictive orifice. Frequently, a coaptation gap yields tricuspid valve regurgitation and over time the "atrialized" portion of the right ventricle may dilate. The highly variable anatomy determines the clinical presentation ranging from asymptomatic to very severe with need for early operation. Echocardiography and magnetic resonance imaging are the most important diagnostic modalities to assess the tricuspid valve as well as ventricular morphology and function. While medical management of asymptomatic patients can be effective for many years, surgical intervention is indicated before development of significant right ventricular dilatation or dysfunction. Onset of symptoms and arrhythmias are further indications for surgery. Modified cone reconstruction of the tricuspid valve is the state-of-the-art approach yielding the best results for most patients. Alternative procedures for select cases include tricuspid valve replacement and bidirectional cavopulmonary shunt depending on patient age and other individual characteristics. Long-term survival after surgery is favorable but rehospitalization and reoperation remain significant issues. Further studies are warranted to identify the optimal surgical strategy and timing before adverse right ventricular remodeling occurs. It is this article's objective to provide a comprehensive review of current literature and an overview on the management of Ebstein's Anomaly. It focuses on imaging, cardiac surgery, and outcome. Additionally, a brief insight into arrhythmias and their management is given. The "future perspectives" summarize open questions and fields of future research.
\end{abstract}

Keywords: Ebstein's anomaly (EA); congenital heart disease; tricuspid valve; cardiac surgery; echocardiography; magnetic resonance imaging

Submitted Sep 08, 2020. Accepted for publication Dec 22, 2020.

doi: $10.21037 / \mathrm{cdt}-20-771$

View this article at: http://dx.doi.org/10.21037/cdt-20-771 


\section{Background, anatomical features, and pathophysiology}

Ebstein's anomaly (EA) accounts for approximately $0.5 \%$ of all congenital heart diseases (CHD) with a prevalence of approximately 1 in 20,000 (1-3). In EA the leaflets of the tricuspid valve adhere to the underlying myocardium of the right ventricle to varying degrees. This is a sequela of failed delamination during embryonic development. As a result, predominantly the septal und inferior leaflets' hinge points are displaced apically causing a shift of the functional tricuspid valve orifice towards the right ventricular outflow tract (RVOT) and partial atrialization of the right ventricle (RV) (4). See Figure 1 for a schematic drawing of EA. The wall of the "atrialized" right ventricle (aRV) is usually thinned and right ventricular contractility reduced. Poor leaflet coaptation causes tricuspid valve regurgitation. With disease progression these characteristics usually entail dilatation of the right atrium (RA), the atrioventricular junction, and the aRV (5). Morphologic changes of the leaflets may also include anterior fenestrations, muscularization, abnormal tethering and-especially regarding the anterior leaflet-tissue redundancy (6). Therefore, the anterior tricuspid valve leaflet can appear sail-like and prolapse into the RVOT (7). All features of EA are highly variable with corresponding clinical characteristics. Carpentier's classification (Table 1) can be used to grade the anatomic changes into types A to $\mathrm{D}$ according to the size and function of the aRV and the mobility of the anterior tricuspid valve leaflet (8). While in the neonate surgical mortality is high, the outcome in adults is generally favorable with good long-term results (9-11).

Tricuspid valve regurgitation and reduced right ventricular contractility result in reduced RV forward flow, dilatation of RA and aRV, as well as thinning of the RV myocardium (12). In this vicious cycle, dilatation of the right heart structures promotes aggravation of tricuspid valve regurgitation.

The altered morphology and function of the right heart in EA can also change left ventricular geometry, lead to fibrosis of the right- and also left-sided myocardium and finally, compromise left heart function (12-14).

Patent foramen ovale and atrial septal defects are common concomitant findings that allow for right to left shunting due to increased right atrial pressure. This leads to varying degrees of desaturation and also bears a risk of paradoxical embolism.

In a series of 539 patients from the Mayo Clinic, $83.9 \%$

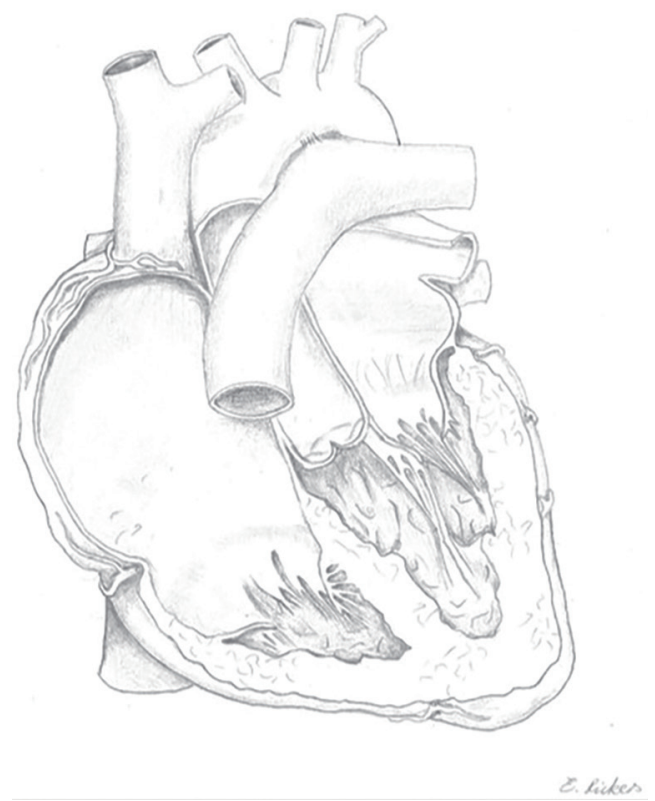

Figure 1 Schematic drawing of typical features of Ebstein's anomaly. The rudimentary septal and inferior leaflets of the tricuspid valve are shown. In comparison to the anterior leaflet of the mitral valve there is marked apical displacement of the leaflets' hinge points. The leaflets are tethered and unable to move freely. The right atrium is enlarged and the right ventricle clearly divided into an atrialized and a functional part.

of patients had atrial septal defects or a patent foramen ovale, $4.3 \%$ had ventricular septal defects and $5.9 \%$ had pulmonary stenosis requiring surgical intervention. Other associated cardiac defects were less common. Associated electrophysiologic abnormalities were accessory conduction pathways in $13.7 \%$ and atrioventricular nodal re-entry tachycardia in $3.3 \%$ (11). Other authors report a similar proportion of ventricular preexcitation/accessory atrioventricular pathways for patients with EA in $10 \%$ to $25 \%(10,15-20)$. One of the frequent late complications of EA are atrial tachycardias (15) predisposing to ventricular tachyarrhythmias in the context of preexcitation. We present the following article in accordance with the Narrative Review reporting checklist (available at http:// dx.doi.org/10.21037/cdt-20-771).

\section{Genetic and environmental factors}

The role of genetics in EA is incompletely understood. There is an association with abnormal left ventricular morphology and function, with left ventricular non- 
Table 1 Carpentier's Classification

\begin{tabular}{ll}
\hline Type & \multicolumn{1}{c}{ Characteristics } \\
\hline Type A & Septal and inferior leaflets: moderate displacement \\
& Anterior leaflet: large; moves freely \\
& aRV: small; contractile wall \\
& fRV: adequate \\
& Septal and inferior leaflets: marked displacement; \\
Type B & septal leaflet hypoplastic and adherent \\
& Anterior leaflet: large; moves freely \\
& aRV: large; thin, noncontractile wall \\
& fRV: small \\
& Septal and inferior leaflets: marked displacement; \\
Type C & leaflets may be severely hypoplastic \\
& Anterior leaflet: restricted motion, moderate \\
& attachment (chordae, fibrous bands) \\
& aRV: large; thin, noncontractile wall \\
& fRV: very small \\
"Tricuspid sac": leaflet tissue nearly completely & adherent to the ventricle; restrictive \\
& Opening to the infundibulum at the site of the \\
& anteroseptal commissure
\end{tabular}

Carpentier's Classification (8); aRV, atrialized right ventricle; fRV, functional right ventricle; RV, right ventricle.

compaction in about $18 \%$ of cases (17). In a case-control study of 4,390 patients with cardiovascular malformations including 47 patients with EA and 3,572 controls, the odds to develop EA was significantly elevated for twins, positive family history of cardiovascular malformations, as well as maternal benzodiazepine exposure (2). These findings suggest genetic and environmental factors in the development of EA. Sequencing of MYH6 and MYH7 in a German family with left ventricular non-compaction revealed a mutation in MYH7 exclusively present in the nine affected family members, 4 of which also had EA (21). In a cohort analysis of 141 unrelated patients with EA, Postma et al. found $8 \mathrm{MYH} 7$ mutations by next-generation sequencing and direct DNA sequencing of MYH7. Six patients with confirmed MYH7 mutations also had left ventricular non-compaction (22).

In the 1970's, retrospective studies suggested a strong association of maternal lithium use during pregnancy with the development of EA. This was not confirmed by more recent studies showing a moderately elevated relative risk to develop any type of CHD in maternal lithium use, but not EA in particular (23). Similarly, a cohort study involving 1,325,563 pregnancies between 2000 and 2010 in the U.S. found a dose-dependent increased adjusted risk ratio for cardiac malformations amidst infants exposed to lithium of 1.65 (95\% CI: 1.02 to 2.68). Of note, none of the 663 infants exposed to lithium developed EA but there was an adjusted risk ratio of 2.66 (95\% CI: 1.00 to 7.06 ) for right ventricular outflow tract obstruction defects (3).

\section{Clinical presentation}

Cyanosis, palpitations and poor exercise tolerance are key symptoms in EA. Cyanosis has been reported in approximately $50 \%$ of patients $(18,24-26)$ and can lead to digital clubbing (18). Severe cyanosis was found to be associated with poor exercise tolerance (18). Palpitations are very frequent and constantly related to arrhythmias (18). As such, they can be associated with chest pain, dizziness and syncope $(18,27)$. Dyspnea and fatigue are also common symptoms in EA $(18,27)$. Jugular venous distension is usually not present given the increased right atrial compliance.

\section{Auscultation}

A third and fourth heart sound is regularly present $(18,27,28)$. Additionally, the first and second heart sounds are often split as a consequence of the delayed tricuspid and pulmonary components (18). Crews et al. described a split first heart sound in 10 of 10 patients with EA. This resulted from late closure of the abnormally large anterior tricuspid valve as demonstrated by ultrasound and related to the degree of right bundle branch block (28).

Patients with EA frequently present with a holosystolic murmur $(18,27,28)$ which can be regurgitant, ejection type, or not well defined (27). Some authors describe a precordial systolic thrill (27). A sternal impulse is rarely found $(18,27)$.

\section{Diagnosis}

\section{Electrocardiogram}

Normal electrocardiograms are exceptional in EA. The most common finding is a right bundle branch block (RBBB) with relatively low voltage $(18,27)$. Preexcitation is present in up to one-fourth, and first degree $\mathrm{AV}$ block due to prolonged intra-atrial conduction in up to one- 

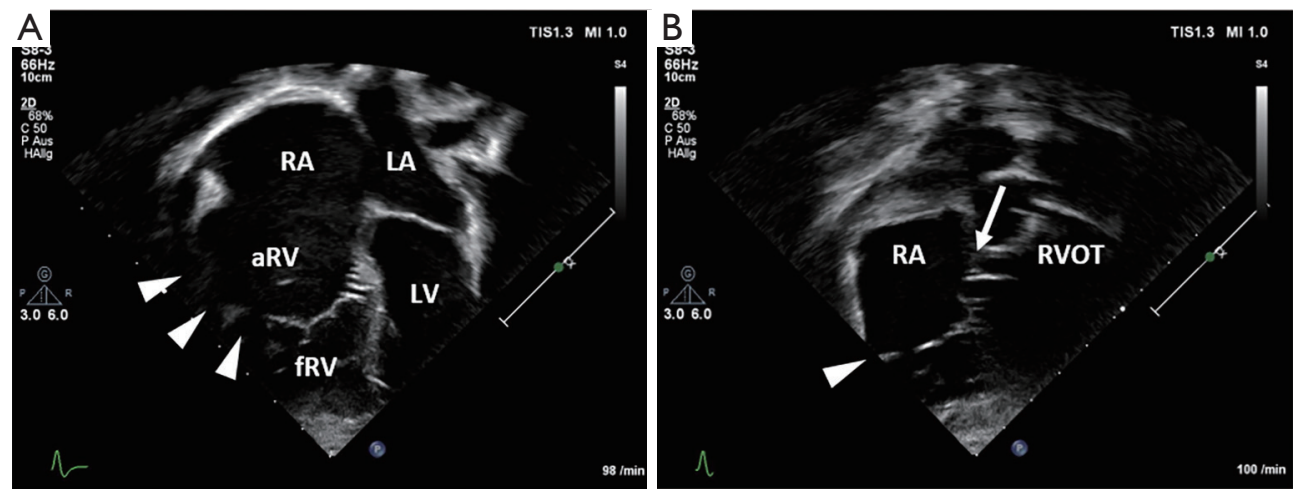

Figure 2 Transthoracic echocardiographic images of Ebstein's anomaly. (A) The apical four-chamber view shows marked apical displacement of the septal tricuspid valve leaflet and tethering of the anterior tricuspid valve leaflet. The atrialized part of the right ventricle, the true tricuspid annulus, and the right atrium are severely enlarged. There is a secundum-type atrial septal defect. (B) shows in- and outflow of the right ventricle. In this image atrialization of the right ventricle appears less evident. fRV, functional right ventricle; aRV, atrialized right ventricle; LV, left ventricle; RA, right atrium; LA, left atrium; arrowhead, anterior leaflet; arrow, septal leaflet; RVOT, right ventricular outflow tract.

third of EA patients (18). Absence of RBBB is suggestive for preexcitation. Typically, large $\mathrm{P}$ waves reflect RA enlargement. Less frequently, conduction delay within the enlarged RA gives rise to a wide $\mathrm{P}$ wave that can be mistaken as a sign of left atrial enlargement (18).

Atrial arrhythmias are frequent. They can develop as a consequence of right atrial enlargement throughout the course of the disease. Structural abnormalities of the atrioventricular conduction system found in EA likely explain the high incidence of accessory pathways (29). You will find a more detailed description of arrhythmias in the treatment section below.

\section{Chest radiography}

On chest radiography, the usually enlarged heart has a round silhouette with a small pedicle similar to pericardial effusion caused by enlarged RA and aRV $(18,27)$. An increased cardiothoracic ratio is frequently present $(18,24,25,27)$. Pulmonary vasculature is usually scarce (27).

\section{Echocardiography}

Echocardiography readily demonstrates the characteristic displacement of the septal and inferior leaflets' hinge points and the subsequent apical shift of the functional TV orifice (see Figure 2). Apical displacement of the septal leaflet in relation to the anterior mitral valve leaflet by $\geq 8 \mathrm{~mm} / \mathrm{m}^{2}$ body surface area-the displacement index-is a diagnostic key feature (30). While the septal and anterior tricuspid valve leaflets can be depicted echocardiographically in fair detail, image quality of the inferior leaflet may be inferior to cardiac magnetic resonance imaging (CMR) (31). Echocardiographic quantification of tricuspid valve regurgitation (TR) is difficult in EA. First of all, the regurgitation jet can be directed inferiorly as a consequence of the orientation of the functional tricuspid valve orifice towards the RV outflow tract. For this reason, the apical four-chamber view is often suboptimal to visualize the full extent of the regurgitation jet (compare Figure $3 A, B$ ). Secondly, in case of multiple jets, vena contracta width cannot accurately be assessed. Additionally, in the context of RV dysfunction and a large coaptation gap the continuous wave Doppler profile is changed with lower than usual velocity, an early peak, and often a high-density signal (32). Finally, given the increased compliance of the often severely dilated RA and aRV, hepatic vein systolic flow reversal is uncommon in severe tricuspid valve regurgitation (32). Of note, increasing inferior angulation of the plane of the tricuspid valve and according inferior direction of the regurgitation jet appears to correlate with increasing severity of morphologic changes (33). 2D echocardiography can be complemented by 3D echocardiography to obtain more detail e.g., of the posterior tricuspid valve leaflet and tethering of the leaflets which can be important for the decision towards valve repair $v s$. replacement $(31,34,35)$.

The assessment of right ventricular function plays an important role in the timing of surgical intervention. 

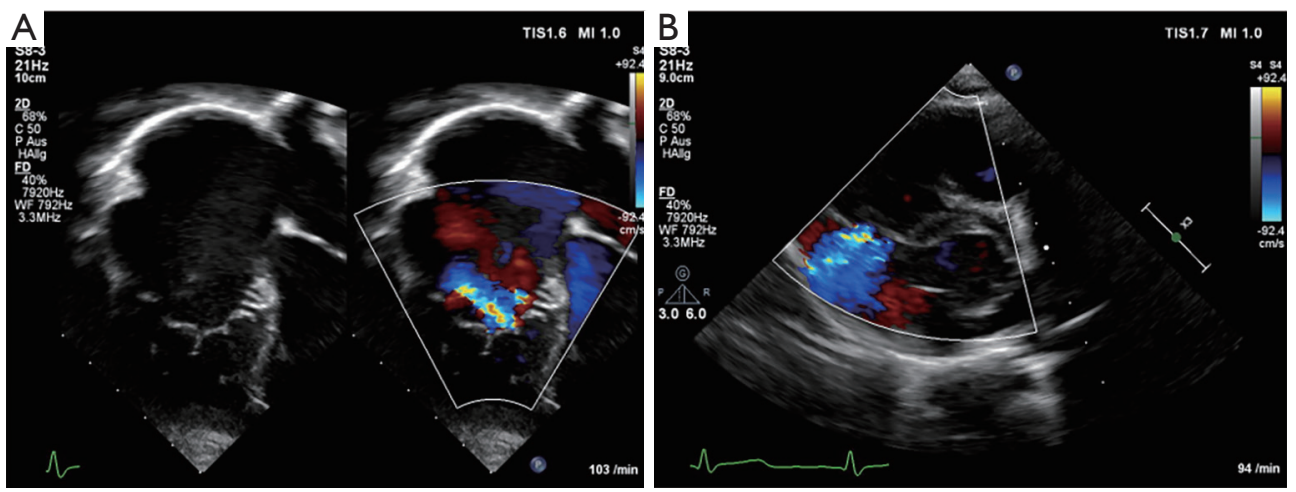

Figure 3 Transthoracic echocardiographic images with Color-Doppler (same patient shown as in Figure 2). (A) Marked apical displacement of the septal tricuspid valve leaflet is noted in the four-chamber view. The Color-Doppler shows only mild to moderate tricuspid regurgitation in image A whereas the parasternal short axis (B) suggests at least moderate tricuspid regurgitation in the same patient.

However, the morphologic changes in EA hinder the use of standard indices like tricuspid annular plane systolic excursion or fractional area change (36). Furthermore, 3D echocardiography for assessment of ventricular function and size can be challenging as increased RV volume may impede complete capture of the whole RV (32). Tissue-Doppler imaging and strain parameters are useful in the assessment of RV function in EA $(26,37)$. Kühn and colleagues compared 6 echocardiographic indices and qualitative assessment of RV function with CMR in 49 unoperated EA patients. They found poor correlation with CMRderived RV ejection fraction (EF) in all echocardiographic parameters but 2D longitudinal strain (36).

Additional cardiac lesions can be well delineated by echocardiography (31) and it is superior to CMR in the detection of shunts at atrial level (32).

\section{Cardiac magnetic resonance imaging}

CMR is an important adjunct to echocardiography and the more accurate and arguably preferable modality to quantify ventricular function and volumes as valuable followup parameters. See Figures 4,5A for examples of CMR images of EA. CMR has played a central role in showing the importance of progressive ventricular dilation and dysfunction in various forms of CHD $(38,39)$. Cine imaging with steady-state free precession (SSFP) is today the predominant MR technique to assess ventricular volumes and function with excellent blood-to-tissue contrast without need for contrast agents, even when ventricular function is poor. On new scanners, SSFP cine imaging can be used in real-time mode, and otherwise requires relatively short, approximately $10 \mathrm{sec}$ breath holds. Measurements of ventricular mass, volume, and ejection fraction are based on a contiguous stack of short-axis (LV) or axial (RV) cine sequences (40) and do not require geometrical assumptions which makes CMR in EA particularly suitable. CMR is now considered the reference standard in CHD for RV volume quantification and pulmonary valve function (41-43). Of note, calculation of the RV volume is not standardized regarding inclusion or exclusion of the aRV. Inclusion of the $\mathrm{aRV}$ allows for an outlook on expected postoperative RV function. Neither are there defined cut-off values for RV function and volumes to prompt surgery. Additionally, blood flow (velocity) data from CMR phase contrast imaging can be useful for the quantification of TR by subtraction of forward stroke volume of the pulmonary artery from total RV stroke volume. In case of an additional ASD or any other shunt lesion, pulmonary to systemic blood flow ratio (Qp:Qs) can be measured using the same technique (32).

In a prospective study of 16 patients with EA by Attenhofer and colleagues, the inferior tricuspid valve leaflet and tricuspid valve fenestrations were better visualized by CMR compared to 2D and 3D echocardiography (31).

With the advent of novel features like tissue characterization by $\mathrm{T} 1$ and $\mathrm{T} 2$ mapping (44-46) and 4D flow imaging $(47,48)$, the importance of CMR for imaging of patients with EA is likely to increase further.

Late gadolinium enhancement (LGE) in various CHD revealed important prognostic associations between solid myocardial fibrosis and adverse clinical outcomes (49-51). In adults with EA, LGE highlighting myocardial scar tissue was a frequent finding within the right atrium and right ventricle (52). However, LGE is less reliable for 

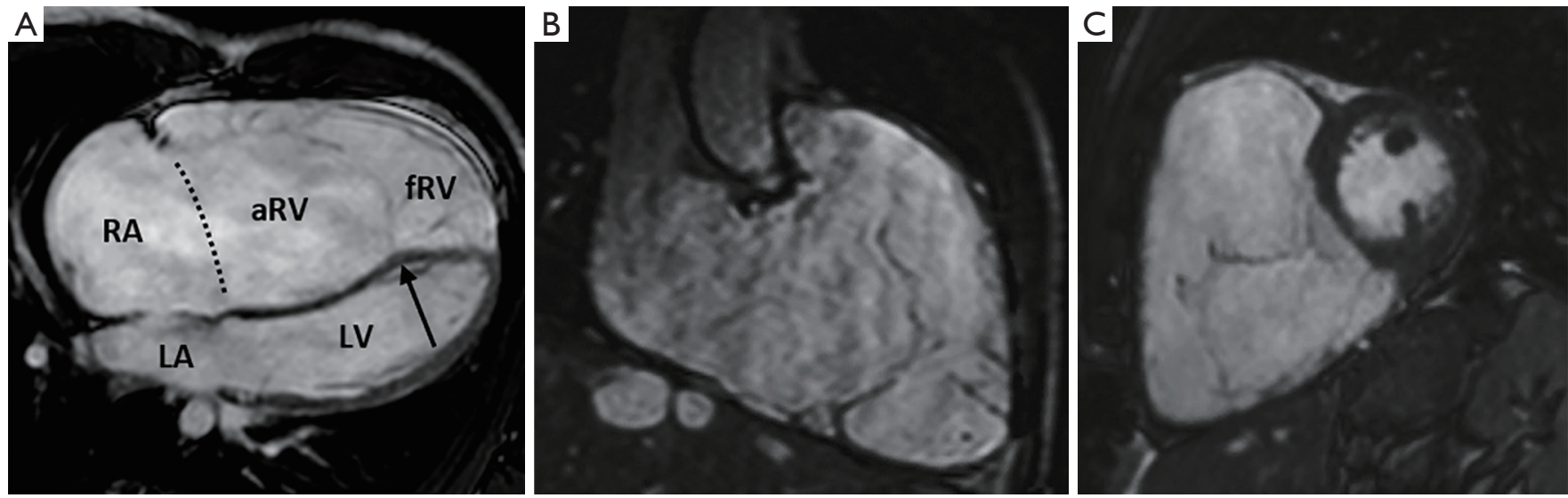

Figure 4 Cardiac magnetic resonance image of Ebstein's anomaly. (A) The four-chamber view depicts severely dilated right heart structures. There is compression of the left atrium and left ventricle. A small atrial septal defect is visible. The atrialized right ventricle (aRV) is very prominent. There is abnormal tethering of the anterior and septal tricuspid valve leaflets. Dotted line, true tricuspid annulus; arrow, hinge point of the septal leaflet; fRV, functional right ventricle; LV, left ventricle; RA, right atrium; LA, left atrium. (B) The oblique view depicts inlet, apical trabecular, and outlet of the right ventricle. (C) The short axis view shows severe displacement of the tricuspid valve and right ventricular dilatation.

detecting diffuse fibrosis, which is common in CHD (53). Extra cellular volume (ECV) fraction from pre- and postcontrast T1 mapping is today an established imaging biomarker for assessing diffuse myocardial fibrosis (54). Diffuse myocardial fibrosis was found in the left ventricle (LV) in congenital aortic stenosis (55), the RV in tetralogy of Fallot (TOF) (56), and the systemic right ventricle after atrial redirection operation in transposition of the great arteries (57). An elevated ECV was found to be associated with adverse clinical parameters such as reduced 6-minute walk distance and higher B-type natriuretic peptide (58) as well as arrhythmias and cardiovascular death in TOF (56). In 44 adolescents and adults with EA assessed by Yang and colleagues, diffuse myocardial fibrosis as detected by ECV was a more frequent finding than focal myocardial fibrosis as detected by LGE (ECV $>30 \%$ in $45 \%$ of patients, LGE in $22 \%$ of patients). Moreover, increased LV ECV correlated with worse LV function and disease severity (51). Considering previous studies in CHD, ECV seems to be a promising prognostic marker in EA.

If CMR is contraindicated or its quality reduced due to artifacts, computed tomography can be considered as a reliable alternative imaging modality (Figure 5B,5C).

In summary, contemporary magnetic resonance imaging scanners offer a comprehensive, multiplane evaluation of cardiac morphology, function and tissue (viability) status independent of body habitus and acoustic windows, making it particularly attractive for adult patients with CHD.

\section{Cardiac catheterization (CC)}

CC is reserved for specific circumstances e.g., for hemodynamic assessment when bidirectional cavopulmonary shunt is considered (32) or coronary artery disease is suspected (59). CC can therefore be omitted in most patients.

Interventional treatment of arrhythmias is described below (see the according treatment section).

\section{Management}

\section{Principles of surgical management}

Patients can often be managed medically for many years. However, the majority requires surgical intervention at some point, in severe forms even in the newborn period or early childhood. In these cases, surgical intervention ranges from tricuspid valve repair to one-and-a-half-ventricle repair to a univentricular approach. This might include an initial Starnes procedure to exclude the right ventricle by tricuspid valve closure with a pericardial patch and creation of an aortopulmonary shunt (60), thus creating functional tricuspid atresia.

The scope of this article lies beyond infancy, when biventricular repair is usually performed and one-and-ahalf-ventricle repair is reserved for cases with very severe 

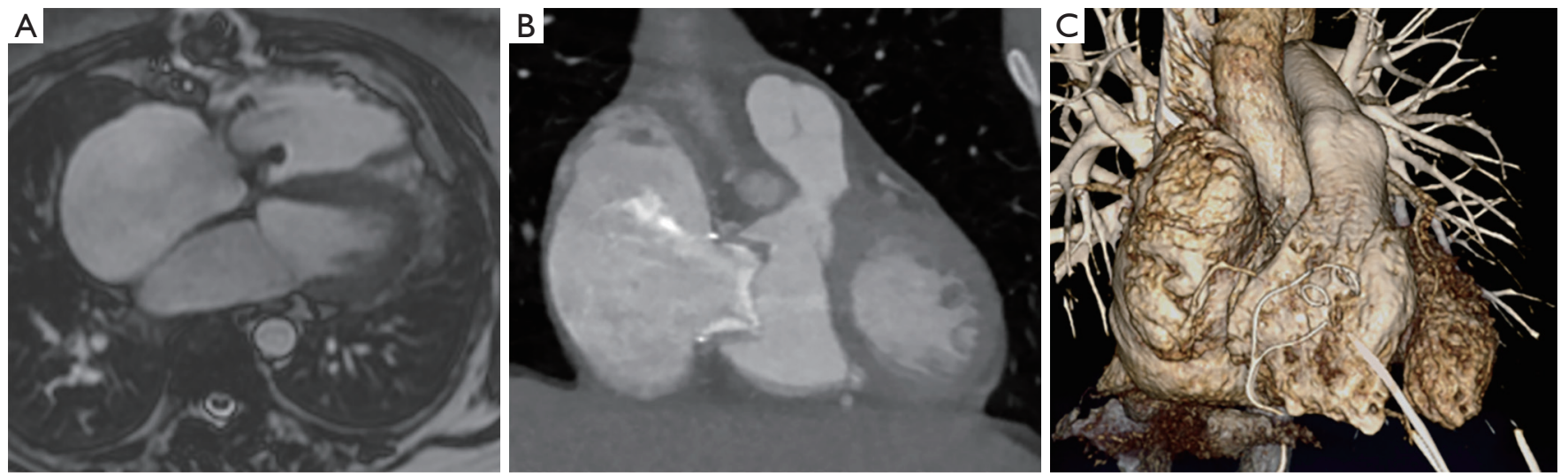

Figure 5 Cardiac magnetic resonance imaging (CMR) and computed tomography (CT) of Ebstein's anomaly. (A) Imaging of a bioprosthetic valve can be routinely carried out with CMR. In this case of a 53-year-old female status post successful tricuspid valve replacement (Hancock valve), the susceptibility artifacts in these standard steady-state free precession gradient cine images are minimal. (B,C) If in case of epicardial pacemaker leads or other causes CMR is contraindicated, CT represents a reliable alternative. The depicted images show a 35-year-old female with Ebstein's anomaly and severe stenosis of a calcified bioprosthetic valve 11 years after tricuspid valve replacement. The $3 \mathrm{D}$ volume rendering $(\mathrm{C})$ shows a severely dilated right atrium. The epicardial pacemaker leads are well delineated.

disease progression and right ventricular failure (61).

Tricuspid valve repair is generally preferred over replacement. Additionally, plication of the aRV, right atrial reduction, (fenestrated) closure of septal defects, and repair of associated lesions are performed. Arrhythmia surgery e.g., intraoperative ablation of accessory pathways and right-sided or bi-atrial maze procedure can complement the procedure (11). Tricuspid valve replacement is an alternative in older patients (reduction of cross-clamp time), severely dysplastic valves precluding repair, severe dilatation of the right atrioventricular junction, and pulmonary hypertension (62).

In failed repair or severe biventricular dysfunction, heart transplantation may be the only alternative in EA (4).

\section{Timing of surgery}

Some authors recommend early intervention in childhood at experienced centers to facilitate valve repair rather than replacement before the onset of progressive morphologic changes (6). More conservative indications for surgery are (I) the onset of symptoms i.e., decreasing exercise tolerance preferably as documented by cardiopulmonary exercise testing or cyanosis, (II) progressive right ventricular enlargement or dysfunction, (III) onset or progression of arrhythmias, or (IV) paradoxical embolism (30) (see Table 2). Hence, careful clinical observation and detection of arrhythmias, progressive right heart dilatation, or deterioration of right ventricular function with appropriate
Table 2 Indications for surgery

- Onset of symptoms

- Deteriorating exercise capacity as measured by CPET

- Cyanosis (oxygen saturation <90\%)

- Progressive RV dilation or dysfunction (e.g., progressive cardiomegaly on chest X-ray)

- Onset or progression of arrhythmias

- Paradoxic embolism

CPET, cardiopulmonary exercise test; RV, right ventricle.

referrals for electrophysiologic study and surgery are crucial (63).

\section{Tricuspid valve repair}

Reconstruction technique for EA has evolved significantly since Hunter and Lillehei published a case report and suggestions for tricuspid valve repair in 1958 (64). For many years the Danielson monocusp reconstruction using the anterior tricuspid valve leaflet to coapt with the ventricular septum was favored (65). This technique brought the functional tricuspid valve annulus up to the level of the true annulus by horizontal plication of the aRV. In contrast, Carpentier subsequently suggested TV repair by mobilizing the anterior and inferior leaflets to form a monocusp with 

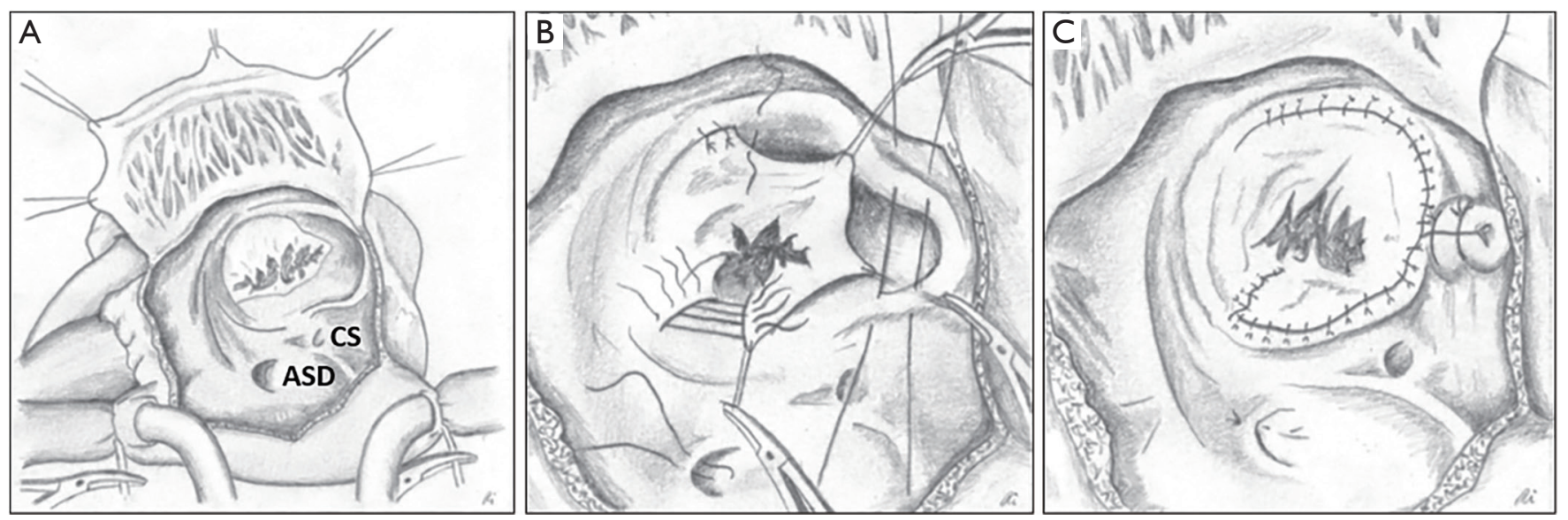

Figure 6 Schematic drawing of the cone reconstruction (25). (A) opened right atrium, displacement of the tricuspid valve towards the right ventricular outflow tract, clearly visible true tricuspid annulus; ASD, atrial septal defect, CS, coronary sinus. (B) mobilization of the anomalous attached parts of the anterior and the whole of the inferior and diminutive septal leaflets, clockwise rotation of the mobilized leaflets to form a cone; plication of the true tricuspid annulus. (C) complete attachment of the base of the newly created cone to the true tricuspid annulus; closure of the atrial septal defect in a valved fashion.

insertion at and enforcement of the true tricuspid valve annulus with an annuloplasty ring. Additionally, vertical plication was used to reduce the size of the aRV (8). Several authors proposed modifications of these or individual other reconstruction techniques. An example of a modification is the approximation of the mobilized anterior papillary muscle to the ventricular septum to improve coaptation of the anterior leaflet, the "Sebening stitch" (66). Quaegebeur and colleagues published a paper on 10 patients with EA in 1999, which were operated on using a modified, ring-less variant of the Carpentier technique (67).

Hetzer and colleagues reduced the size of the valvar annulus by horizontal plication (similar to an "Alfieri-stich") to the extent of the largest developed leaflet according to the level and size of the true annulus. This technique can be used in a broad morphologic spectrum including cases with a small anterior leaflet (68).

The most anatomically correct and nowadays preferred tricuspid valve repair is the cone reconstruction (CR) as described by da Silva et al. in 2007 (25). It involves delamination of all available tricuspid valve tissue and formation of a cone-shaped valve of 360 degrees of valvar tissue. Figure 6 summarizes the most important steps of the $\mathrm{CR}$ in a schematic drawing. The anterior and inferior leaflets are detached from their anomalous origin and attachments as a whole and the inferior leaflet is rotated clockwise to complete the cone. The apical attachment remains at the apex of the right ventricle, whereas the base of the cone is sutured to the true tricuspid annulus. Whenever possible, the septal leaflet is incorporated in the reconstruction depending on the amount of available tissue. In 22 of 40 patients da Silva et al. were able to utilize the septal leaflet for reconstruction in their original series. In most cases, the aRV is longitudinally plicated and the true tricuspid annulus is plicated to match the proximal circumference of the reconstructed valve. The foramen ovale or ostium secundum atrial septal defects are closed in a valved fashion to allow for a reduced degree of right to left shunting (25). The CR can be performed in patients with previous valve surgery if the subvalvar apparatus remained untouched and previous surgery focused on annular maneuvers (69).

Surgeons have modified the CR in many ways. The Mayo Clinic's experience shows that application of a partial annuloplasty ring correlates with freedom from reoperation (70). Further important modifications are selective leaflet augmentation (71) and the above mentioned "Sebening stitch" (66), both to improve coaptation.

\section{Tricuspid valve replacement}

As described above, tricuspid valve replacement can be a viable alternative to repair in select patients. Bioprosthetic valves are generally preferred to mechanical valves as they exhibit good durability and do not require anticoagulation. Mechanical valves can be associated with increased risk 
of embolic events because large valve size and reduced right ventricular contractility can promote disc motion abnormalities and subsequent thrombus formation. Especially in poor right ventricular function they should therefore be avoided.

In infants and young children, the life span of bioprosthetic valves can be reduced due to calcification (66).

Transcatheter valve-in-valve implantation is feasible in degraded bioprosthetic valves. However, results from an international registry study of 81 patients with EA undergoing transcatheter valve-in-valve implantation between 2008 and 2016 were not promising. At the latest follow-up (median follow-up 13 months; 5-27 months), freedom from reintervention or valve dysfunction was only 77 percent (62 of 81 patients) (72). Yet, due to the retrospective nature of this study, a total of 29 different participating institutions with non-standardized treatment algorithms and different types of valves used [Melody (Medtronic, Inc, Minneapolis, Minnesota) or Sapien (Edwards Lifesciences, Irvine, California)] these results warrant further research and should be interpreted with caution.

\section{Bidirectional cavopulmonary shunt}

For the one-and-a-half-ventricle repair, tricuspid valve repair or replacement is combined with a bidirectional cavopulmonary shunt (BCPS) to offload the right ventricle in cases of severe right ventricular dilatation and systolic function impairment. The BCPS significantly decreases right ventricular volume, hence reducing postoperative hemodynamic stress while generating sufficient preload for the left ventricle (6). Despite the many challenges faced in this patient group, the results of 62 patients who underwent one-and-a-half-ventricle repair at the Mayo Clinic are encouraging with low early mortality and good mid-term results (mean follow-up 3.6 \pm 2.6 years). The majority of patients $(88 \%)$ were in NYHA FC I or II at follow-up. Of note, only 3 of 20 patients initially referred for transplant evaluation were listed following surgery (61). The Stanford group reported similar favorable results in EA repair with conjunct BCPS for RV unloading in 31 patients (55\%) of an entire group of 57 nonneonatal EA patients resulting in no early or late mortality. Criteria for BCPS were inadequate $\mathrm{RV}$ function as demonstrated by preoperative cyanosis and obstruction of the reconstructed or replaced tricuspid valve after separation from cardiopulmonary bypass as measured by transesophageal echocardiography (73).

\section{Treatment of arrhythmias}

As mentioned above, in EA there is a high prevalence of accessory pathways, both manifest and concealed (74). Multiple accessory pathways can be observed in approximately $50 \%$ of cases $(75,76)$. Additionally, atrial flutter and fibrillation are frequent findings (24). In the presence of ventricular preexcitation, this poses a high risk for lethal ventricular arrhythmias. Previous tricuspid valve surgery can complicate catheter ablation of accessory pathways. Therefore, even if preexcitation is absent on the surface ECG and there is no history of supraventricular tachycardias, electrophysiologic study (EPS) and if needed catheter ablation before intervention on the tricuspid valve is reasonable $(4,59,77)$. Catheter ablation is the preferred treatment option for accessory pathways $(74,78,79)$. Even though 3D mapping (80) and other advances in catheter technology improve outcomes (78) high recurrence rates remain an issue in EA (81).

At Boston Children's Hospital, 42 of 74 consecutive EA patients underwent EPS prior to cone reconstruction from 2006 to 2012 (median age at the time of CR 12.1 years; range 0.2-56.2 years) (16). Twenty-nine patients had significant arrhythmia substrates with Wolff-ParkinsonWhite (WPW) syndrome most common and in 3 cases asymptomatic. Examples of other substrates were atrial flutter, atrial fibrillation and ventricular tachycardias. Eight of 19 patients without preoperative evidence of rhythm disorders had a positive EPS (16). Similarly, Chauvaud et al. found arrhythmias in 45 of 98 patients undergoing surgery for EA from 1980 to 1999 at the hospital Broussais in Paris, France. In this series the most frequent arrhythmias were atrial tachycardias. Interestingly, patients presenting with arrhythmias were significantly older than those without (mean age 33 vs. 21 years) (24) suggesting secondary alterations throughout the course of the disease.

Wackel and colleagues assessed 143 young patients with a median age of 10 years (0.1-20.9 years) who underwent cone reconstruction at the Mayo Clinic from 2007 to 2015 (20). They found preoperative arrhythmias in $31 \%$ of patients. In this young cohort WPW syndrome/ventricular preexcitation was the predominant finding ( $20 \%$ of cases), followed by supraventricular tachycardias other than atrial flutter and atrial fibrillation in $17 \%$ of cases. Other arrhythmias were less frequent (20). This confirms the observation that atrial arrhythmias like atrial flutter and atrial fibrillation tend to develop at later stages. Of note, in this young age group recurrence of arrhythmias was low (mean follow-up 2.9 years) (20). 
An alternative treatment for accessory pathways (25) and atrioventricular nodal reentrant tachycardias is surgical division or ablation (82).

In adults with EA, paroxysmal atrial flutter and atrial fibrillation are frequent $(24,78)$. They can be treated by rightsided or bi-atrial maze procedure during corrective surgery. In persistent or permanent atrial flutter or fibrillation a biatrial maze procedure may be advantageous (83).

\section{Isolated closure of patent foramen ovale or atrial septal defects}

Isolated interventional closure of $\mathrm{PFO} / \mathrm{ASD}$ is a controversial topic. It can be considered in case of cyanosis (oxygen saturation at rest $<90 \%$ ) or paradoxical embolism (4) whereas for other authors paradoxical embolism represents an indication for corrective surgery (30). Patients should undergo careful evaluation before isolated closure of $\mathrm{PFO} /$ ASD for risk of hemodynamic deterioration following increased right ventricular preload and pressure (4).

\section{Outcome}

In experienced centers, early mortality is low in tricuspid valve repair or replacement. The largest series of EA patients includes 539 patients with 604 operations from 1972 to 2006 at the Mayo Clinic. Three-hundred-thirty-seven patients underwent tricuspid valve replacement (approximately 300 bioprosthetic valves; remaining patients received mechanical valves; exact number not given) and 182 patients tricuspid valve repair. Tricuspid valve repair was based on a monocusp reconstruction with according modifications as required by EA variant. The 30-day mortality fell from $5.9 \%$ for the entire cohort to $2.7 \%$ after 2001 . Overall reoperation-free survival (TV or other) was $95 \%$, $86 \%, 74 \%, 62 \%$, and $46 \%$ at $1,5,10,15$, and 20 years, respectively. Reoperation-free survival in patients after tricuspid valve repair was slightly higher with $98 \%$, $93 \%, 84 \%, 73 \%$, and $56 \%$ at $1,5,10,15$, and 20 years, respectively. Of note, patient characteristics differed in several aspects between the two groups (11). The results of 122 patients from the German Heart Center in Munich from 1976 to 2007 with a higher proportion of valve repair (90.2\% patients underwent valve repair vs. $35.1 \%$ at the Mayo Clinic) from the era before cone reconstruction were similar with freedom from reoperation of $79.9 \%, 61.9 \%$, and $58.0 \%$ at 10,20 , and 25 years, respectively. Early mortality was also low with 2 hospital deaths (9).

Given the more recent introduction of the cone reconstruction, long term results for comparison with these data are lacking. In a series of 235 patients with EA who underwent cone reconstruction at the Mayo Clinic from 2007 to 2015, overall survival at 6 years was $98 \%$ and freedom from TV replacement and late reoperation were $97.1 \%$ and $97.3 \%$, respectively. Importantly and in the context of sustained reduction in tricuspid regurgitation, a progressive decline in right ventricular size and late improvement of right ventricular function was observed (10).

\section{Open questions and future perspectives}

In the majority of patients, RV function improves postoperatively after an initial decline independent of surgical strategy $(10,26)$. Additionally, there is a tendency towards progressive reduction of RV volume (10). However, even when tricuspid valve repair is carried out early $\mathrm{RV}$ performance cannot be restored to a satisfactory level in some cases. Structural RV myocardial changes have been described in EA which may be accountable for reduced RV performance $(12,14,52)$. In this context, the optimal timing for surgery remains unclear. Badiu and colleagues found worse functional status and cardiothoracic ratio of $>0.6$ to be significant risk factors of poor outcome in a series of 122 EA patients undergoing surgery suggesting better results at early stages of the disease (9). Nevertheless, the question whether early tricuspid valve surgery in patients with stable and satisfactory RV parameters yields better long-term results warrants further studies. Especially further research on RV remodeling is needed to clarify these observations. As novel CMR techniques become more widely used some of these questions on EA will unravel. This can promote better understanding of the disease and guide tailored treatment to the patient's individual needs. Tissue characterization may play an important role and aid in classification of patients' characteristics and the choice of advanced treatment strategies. These include cell-based regenerative therapies which are already under investigation as a resort to poor RV function (62).

Ultimately, treatment of arrhythmias requires further attention. The individual's risk of arrhythmias needs to be better defined to establish algorithms for the diagnostic process. High recurrence rates of all described arrhythmias in EA regardless of the type of treatment-interventional or surgical—warrant improved treatment strategies $(81,82)$. 


\section{Summary: key facts}

* Ebstein's anomaly is a malformation not only of the tricuspid valve, but also the right ventricle with a wide morphologic variety and a heterogeneous spectrum of clinical presentation.

* The currently preferred surgical strategy is the cone reconstruction of the tricuspid valve with promising short and long-term results.

* Atrial tachyarrhythmias and accessory pathways are frequent comprising a predisposition to lethal ventricular tachyarrhythmias.

* This arrhythmogenic susceptibility warrants a low threshold for electrophysiologic assessment prior to surgery and percutaneous or surgical treatment if needed.

* Timing of surgery remains subject of further evaluation to improve postoperative right ventricular performance.

\section{Acknowledgments}

We would like to thank Eva Rickers for creating the art work.

Funding: None.

\section{Footnote}

Provenance and Peer Review: This article was commissioned by the Guest Editors (Yskert von Kodolitsch, Harald Kaemmerer, Koichiro Niwa) for the series "Current Management Aspects in Adult Congenital Heart Disease (ACHD): Part IV" published in Cardiovascular Diagnosis and Therapy. The article has undergone external peer review.

Reporting Checklist: The authors have completed the Narrative Review reporting checklist. Available at http:// dx.doi.org/10.21037/cdt-20-771

Conflicts of Interest: All authors have completed the ICMJE uniform disclosure form (available at http:// dx.doi.org/10.21037/cdt-20-771). The series "Current Management Aspects in Adult Congenital Heart Disease (ACHD): Part IV" was commissioned by the editorial office without any funding or sponsorship. The authors have no other conflicts of interest to declare.

Ethical Statement: The authors are accountable for all aspects of the work in ensuring that questions related to the accuracy or integrity of any part of the work are appropriately investigated and resolved.

Open Access Statement: This is an Open Access article distributed in accordance with the Creative Commons Attribution-NonCommercial-NoDerivs 4.0 International License (CC BY-NC-ND 4.0), which permits the noncommercial replication and distribution of the article with the strict proviso that no changes or edits are made and the original work is properly cited (including links to both the formal publication through the relevant DOI and the license). See: https://creativecommons.org/licenses/by-nc-nd/4.0/.

\section{References}

1. Liu Y, Chen S, Zühlke L, et al. Global birth prevalence of congenital heart defects 1970-2017: Updated systematic review and meta-analysis of 260 studies. Int J Epidemiol 2019;48:455-63.

2. Correa-Villaseñor A, Ferencz C, Neill CA, et al. Ebstein's malformation of the tricuspid valve: Genetic and environmental factors. Teratology 1994;50:137-47.

3. Patorno E, Huybrechts KF, Bateman BT, et al. Lithium Use in Pregnancy and the Risk of Cardiac Malformations. N Engl J Med 2017;376:2245-54.

4. Baumgartner H, De Backer J, Babu-Narayan SV, et al. 2020 ESC Guidelines for the management of adult congenital heart disease. Eur Heart J 2021;42:563-645.

5. Anderson KR, Lie JT. Pathologic anatomy of Ebstein's anomaly of the heart revisited. Am J Cardiol 1978;41:739-45.

6. Dearani JA, Mora BN, Nelson TJ, et al. Ebstein anomaly review: What's now, what's next? Expert Rev Cardiovasc Ther 2015;13:1101-9.

7. Schreiber C, Cook A, Ho SY, et al. Morphologic spectrum of Ebstein's malformation: Revisitation relative to surgical repair. J Thorac Cardiovasc Surg 1999;117:148-55.

8. Carpentier A, Chauvaud S, Mace L, et al. A new reconstructive operation for Ebstein's anomaly of the tricuspid valve. J Thorac Cardiovasc Surg 1988;96:92-101.

9. Badiu CC, Schreiber C, Hörer J, et al. Early timing of surgical intervention in patients with Ebstein's anomaly predicts superior long-term outcome. Eur J Cardiothorac Surg 2010;37:186-92.

10. Holst KA, Dearani JA, Said S, et al. Improving Results of Surgery for Ebstein Anomaly: Where Are We After 235 Cone Repairs? Ann Thorac Surg 2018;105:160-8.

11. Brown ML, Dearani JA, Danielson GK, et al. The 
outcomes of operations for 539 patients with Ebstein anomaly. J Thorac Cardiovasc Surg. 2008;135:1120-36.

12. Celermajer DS, Dodd SM, Greenwald SE, et al. Morbid anatomy in neonates with Ebstein's anomaly of the tricuspid valve: Pathophysiologic and clinical implications. J Am Coll Cardiol 1992;19:1049-53.

13. Benson LN, Child JS, Schwaiger M, et al. Leftventricular geometry and function in adults with Ebstein's anomaly of the tricuspid valve. Circulation 1987;75:353-9.

14. Lee AHS, Moore IE, Fagg NLK, et al. Histological changes in the left and right ventricle in hearts with Ebstein's malformation and tricuspid valvar dysplasia: A morphometric study of patients dying in the fetal and perinatal periods. Cardiovasc Pathol 1995;4:19-24.

15. Watson H. Natural history of Ebstein's anomaly of tricuspid valve in childhood and adolescence An international co-operative study of 505 cases. Br Heart J 1974;36:417-27.

16. Shivapour JKL, Sherwin ED, Alexander ME, et al. Utility of preoperative electrophysiologic studies in patients with Ebstein 's anomaly undergoing the Cone procedure. Heart Rhythm 2014;11:182-6.

17. Attenhofer Jost CH, Connolly HM, O'Leary PW, et al. Left heart lesions in patients with ebstein anomaly. Mayo Clin Proc 2005;80:361-8.

18. Bialostozky D, Horwitz S, Espino-Vela J. Ebstein's malformation of the tricuspid valve: A review of 65 cases. Am J Cardiol 1972;29:826-36.

19. Celermajer DS, Bull C, Mrcp MA, et al. Presentation and Outcome From Fetus to Adult. J Am Coll Cardiol 1994;23:170-6.

20. Wackel P, Cannon B, Dearani J, et al. Arrhythmia after cone repair for Ebstein anomaly: The Mayo Clinic experience in 143 young patients. Congenit Heart Dis 2018;13:26-30.

21. Budde BS, Binner P, Waldmüller S, et al. Noncompaction of the ventricular myocardium is associated with a de novo mutation in the $\beta$-myosin heavy chain gene. PLoS One 2007;2:e1362.

22. Postma AV, Van Engelen K, Van De Meerakker J, et al. Mutations in the sarcomere gene MYH7 in Ebstein anomaly. Circ Cardiovasc Genet 2011;4:43-50.

23. Cohen LS, Friedman JM, Jefferson JW, et al. A Reevaluation of Risk of In Utero Exposure to Lithium. JAMA 1994;271:146-50.

24. Chauvaud SM, Brancaccio G, Carpentier AF. Cardiac arrhythmia in patients undergoing surgical repair of Ebstein's anomaly. Ann Thorac Surg 2001;71:1547-52.
25. da Silva JP, Baumgratz JF, da Fonseca L, et al. The cone reconstruction of the tricuspid valve in Ebstein's anomaly. The operation: early and midterm results. J Thorac Cardiovasc Surg 2007;133:215-23.

26. Hetzer R, Hacke P, Javier M, et al. The long-term impact of various techniques for tricuspid repair in Ebstein's anomaly. J Thorac Cardiovasc Surg 2015;150:1212-9.

27. Kumar AE, Fyler DC, Miettinen OS, et al. Ebstein's anomaly. Clinical profile and natural history. Am J Cardiol 1971;28:84-95.

28. Crews TL, Pridie RB, Benham R, et al. Ausculatory and phonocardiographic findings in Ebstein's anomaly: correlation of first heart sound with ultrasonic records of tricuspid valve movement. Br Heart J 1971;33:610.

29. Ho SY, Goltz D, McCarthy K, et al. The atrioventricular junctions in Ebstein malformation. Heart 2000;83:444-9.

30. Attenhofer Jost CH, Connolly HM, Dearani JA, et al. Ebstein's anomaly. Circulation 2007;115:277-85.

31. Attenhofer Jost CH, Edmister WD, Julsrud PR, et al. Prospective comparison of echocardiography versus cardiac magnetic resonance imaging in patients with Ebstein's anomaly. Int J Cardiovasc Imaging 2012;28:1147-59.

32. Qureshi MY, O’Leary PW, Connolly HM. Cardiac imaging in Ebstein anomaly. Trends Cardiovasc Med 2018;28:403-9.

33. Silverman N. Anatomic Definition and Imaging of Ebstein's Malformation. In: Redington AN, Arsdell GS Van, Anderson RH, editors. Congenital Diseases in the Right Heart. London: Springer; 2009. p. 271-92.

34. Booker OJ, Nanda NC. Echocardiographic assessment of Ebstein's anomaly. Echocardiography 2015;32 Suppl 2:S177-88.

35. Patel V, Nanda NC, Rajdev S, et al. Live/Real Time Three-Dimensional Transthoracic Echocardiographic Assessment of Ebstein 's Anomaly. Echocardiography 2005;22:847-54.

36. Kühn A, Meierhofer C, Rutz T, et al. Non-volumetric echocardiographic indices and qualitative assessment of right ventricular systolic function in Ebstein's anomaly: Comparison with CMR-derived ejection fraction in 49 patients. Eur Heart J Cardiovasc Imaging 2016;17:930-5.

37. Perdreau E, Tsang V, Hughes ML, et al. Change in biventricular function after cone reconstruction of Ebstein's anomaly: An echocardiographic study. Eur Heart J Cardiovasc Imaging 2018;19:808-15.

38. Kilner PJ, Geva T, Kaemmerer H, et al. Recommendations for cardiovascular magnetic resonance in adults with congenital heart disease from the respective working 
groups of the European Society of Cardiology. Eur Heart J 2010;31:794-805.

39. Burchill LJ, Mertens L, Broberg CS. Imaging for the Assessment of Heart Failure in Congenital Heart Disease Ventricular Function and Beyond. Heart Fail Clin 2014;10:9-22.

40. Alfakih K, Thiele H, Plein S, et al. Comparison of Right Ventricular Volume Measurement Between Segmented K-Space Gradient-Echo and Steady-State Free Precession Magnetic Resonance Imaging. J Magn Reson Imaging 2002;16:253-8.

41. Bonello B, Kilner PJ. Review of the role of cardiovascular magnetic resonance in congenital heart disease, with a focus on right ventricle assessment. Arch Cardiovasc Dis 2012;105:605-13.

42. Orwat S, Diller GP, Baumgartner H. Imaging of congenital heart disease in adults: Choice of modalities. Eur Heart J Cardiovasc Imaging 2014;15:6-17.

43. Mooij CF, De Wit CJ, Graham DA, et al. Reproducibility of MRI measurements of right ventricular size and function in patients with normal and dilated ventricles. J Magn Reson Imaging 2008;28:67-73.

44. Kathiria NN, Higgins CB, Ordovas KG. Advances in MR Imaging Assessment of Adults with Congenital Heart Disease. Magn Reson Imaging Clin N Am 2015;23:35-40.

45. Burchill LJ, Huang J, Tretter JT, et al. Noninvasive Imaging in Adult Congenital Heart Disease. Circ Res 2017;120:995-1014.

46. Marcotte F, Poirier N, Pressacco J, et al. Evaluation of Adult Congenital Heart Disease by Cardiac Magnetic. Congenit Heart Dis 2009;4:216-30.

47. Sievers H-H, Putman LM, Kheradvar A, et al. 4D flow streamline characteristics of the great arteries twenty years after Lecompte and direct spiral arterial switch operation (DSASO) in simple TGA. Glob Cardiol Sci Pract 2016;2016:e201629.

48. Fredriksson AG, Zajac J, Eriksson J, et al. 4-D blood flow in the human right ventricle. Am J Physiol Heart Circ Physiol 2011;301:H2344-50.

49. Babu-Narayan S V, Kilner PJ, Li W, et al. Ventricular Fibrosis Suggested by Cardiovascular Magnetic Resonance in Adults With Repaired Tetralogy of Fallot and Its Relationship to Adverse Markers of Clinical Outcome. Circulation 2006;405-13.

50. Rathod RH, Prakash A, Powell AJ, et al. Myocardial Fibrosis Identified by Cardiac Magnetic Resonance Late Gadolinium Enhancement Is Associated With Adverse Ventricular Mechanics and Ventricular Tachycardia Late
After Fontan Operation. J Am Coll Cardiol 2010;5 5:1721-8.

51. Yang D, Li X, Sun JY, et al. Cardiovascular magnetic resonance evidence of myocardial fibrosis and its clinical significance in adolescent and adult patients with Ebstein's anomaly. J Cardiovasc Magn Reson 2018;20:69.

52. Ciepłucha A, Trojnarska O, Kociemba A, et al. Clinical aspects of myocardial fibrosis in adults with Ebstein 's anomaly. Heart Vessels 2018;33:1076-85.

53. Broberg CS, Chugh SS, Conklin C, et al. Quantification of Diffuse Myocardial Fibrosis and Its Association With Myocardial Dysfunction in Congenital Heart Disease. Circ Cardiovasc Imaging 2010;3:727-734.

54. Miller CA, Naish JH, Bishop P, et al. Comprehensive Validation of Cardiovascular Magnetic Resonance Techniques for the Assessment of Myocardial Extracellular Volume. Circ Cardiovasc Imaging 2013;6:373-83.

55. Dusenbery SM, Jerosch-Herold M, Rickers C, et al. Myocardial Extracellular Remodeling Is Associated With Ventricular Diastolic Dysfunction in Children and Young Adults With Congenital Aortic Stenosis. J Am Coll Cardiol 2014;63:1778-85.

56. Chen CA, Dusenbery SM, Valente AM, et al. Myocardial ECV Fraction Assessed by CMR Is Associated With Type of Hemodynamic Load and Arrhythmia in Repaired Tetralogy of Fallot. JACC Cardiovasc Imaging 2016;9:1-10.

57. Plymen CM, Sado DM, Taylor AM, et al. Diffuse myocardial fibrosis in the systemic right ventricle of patients late after Mustard or Senning surgery : an equilibrium contrast cardiovascular magnetic resonance study. Eur Heart J Cardiovasc Imaging 2013;14:963-8.

58. Broberg CS, Huang J, Hogberg I, et al. Diffuse LV Myocardial Fibrosis and its Clinical Associations in Adults With Repaired Tetralogy of Fallot. JACC Cardiovasc Imaging 2016;9:86-7.

59. Stout KK, Daniels CJ, Aboulhosn JA, et al. 2018 AHA/ ACC Guideline for the Management of Adults With Congenital Heart Disease: A Report of the American College of Cardiology/American Heart Association Task Force on Clinical Practice Guidelines. Vol. 139, Circulation. 2019. 698-800 p.

60. Starnes VA, Pitlick PT, Bernstein D, et al. Ebstein's anomaly appearing in the neonate: A new surgical approach. J Thorac Cardiovasc Surg 1991;101:1082-7.

61. Raju V, Dearani JA, Burkhart HM, et al. Right ventricular unloading for heart failure related to Ebstein malformation. Ann Thorac Surg 2014;98:167-73.

62. Holst KA, Connolly HM, Dearani JA. Ebstein' s Anomaly. Methodist Debakey Cardiovasc J 2019;15:138-44. 
63. Holst K, Ammash NM, Dearani JA. Ebstein anomaly. In: Gatzoulis MA, Webb GD, Daubeney PEF, editors. Diagnosis and Management of Adult Congenital Heart Disease Third Edit. Philadelphia: Elsevier; 2018. p. 442-9.

64. Hunter SW, Lillehei CW. Ebstein's malformation of the tricuspid valve; study of a case together with suggestion of a new form of surgical therapy. Dis Chest 1958;33:297-304.

65. Danielson GK, Fuster V. Surgical Repair of Ebstein 's Anomaly. Ann Surg 1982;196:499-504.

66. Cetta F, Dearani JA, O'Leary PW, et al. Ebstein Anomaly. In: Allen HD, Shaddy RE, Penny DJ, et al., editors. Moss and Adams' Heart Disease in Infants, Children, and Adolescents: Including the Fetus and Young Adult. 9th ed. Philadelphia: Lippincott Williams \& Wilkins; 2016. p. 960-80.

67. Quaegebeur JM, Sreeram N, Fraser AG, et al. Surgery for Ebstein's anomaly: The clinical and echocardiographic evaluation of a new technique. J Am Coll Cardiol 1991;17:722-8.

68. Hetzer R, Nagdyman N, Ewert P, et al. A modified repair technique for tricuspid incompetence in Ebstein's anomaly. J Thorac Cardiovasc Surg 1998;115:857-68.

69. Dearani JA, Said SM, Burkhart HM, et al. Strategies for Tricuspid Re-Repair in Ebstein Malformation Using the Cone Technique. Ann Thorac Surg 2013;96:202-08.

70. Anderson HN, Dearani JA, Said SM, et al. Cone Reconstruction in Children with Ebstein Anomaly : The Mayo Clinic Experience. Congenit Heart Dis 2014;9:266-71.

71. Dearani JA, Said SM, O’Leary PW, et al. Anatomic repair of Ebstein's malformation: Lessons learned with cone reconstruction. Ann Thorac Surg 2013;95:220-6.

72. Taggart NW, Cabalka AK, Eicken A, et al. Outcomes of Transcatheter Tricuspid Valve-in-Valve Implantation in Patients With Ebstein Anomaly. Am J Cardiol 2018;121:262-8.

73. Malhotra SP, Petrossian E, Reddy VM, et al. Selective Right Ventricular Unloading and Novel Technical Concepts in Ebstein's Anomaly. Ann Thorac Surg 2009;88:1975-81.

74. Hebe J. Ebstein s Anomaly in Adults . Arrhythmias : Diagnosis and Therapeutic Approach. Thorac Cardiovasc Surg 2000;48:214-9.

75. Pressley JC, Wharton JM, Tang ASL, et al. Effect of
Ebstein's anomaly on short- and long-term outcome of surgically treated patients with Wolff-Parkinson-White syndrome. Circulation 1992;86:1147-55.

76. Cappato R, Schlüter M, Weiß C, et al. Radiofrequency current catheter ablation of accessory atrioventricular pathways in Ebstein's anomaly. Circulation 1996;94:376-83.

77. Khairy P, van Hare GF, Balaji S, et al. PACES/HRS Expert Consensus Statement on the Recognition and Management of Arrhythmias in Adult Congenital Heart Disease. Can J Cardiol 2014;30:e1-63.

78. Hernández-Madrid A, Paul T, Abrams D, et al. Arrhythmias in congenital heart disease: A position paper of the European Heart Rhythm Association (EHRA), Association for European Paediatric and Congenital Cardiology (AEPC), and the European Society of Cardiology (ESC) Working Group on Grown-up Congeni. Europace 2018;20:1719-53.

79. Wei W, Zhan X, Xue Y, et al. Features of accessory pathways in adult Ebstein's anomaly. Europace 2014;16:1619-25.

80. Walsh EP. Interventional Electrophysiology in Patients With Congenital Heart Disease. Circulation 2007;115:3224-34.

81. Chetaille P, Walsh EP, Triedman JK. Outcomes of radiofrequency catheter ablation of atrioventricular reciprocating tachycardia in patients with congenital heart disease. Heart Rhythm 2004;1:168-73.

82. Khositseth A, Danielson GK, Dearani JA, et al. Supraventricular tachyarrhythmias in Ebstein anomaly: Management and outcome. J Thorac Cardiovasc Surg 2004;128:826-33.

83. Stulak JM, Sharma V, Cannon BC, et al. Optimal Surgical Ablation of Atrial Tachyarrhythmias During Correction of Ebstein Anomaly. Ann Thorac Surg 2015;99:1700-5.

Cite this article as: Neumann S, Rüffer A, Sachweh J, Biermann D, Herrmann J, Jerosch-Herold M, Hazekamp M, Sinning C, Zengin E, Blankenberg S, Girdauskas E, Reichenspurner H, Kehl T, Müller G, Kozlik-Feldmann R Rickers C. Narrative review of Ebstein's anomaly beyond childhood: Imaging, surgery, and future perspectives. Cardiovasc Diagn Ther 2021;11(6):1310-1323. doi: 10.21037/ cdt-20-771 